\title{
Investigating the relation of value inclinations and social identity-adoption (among the male high school students of the city of Myandoab in the educational year of 2012-2013)
}

\author{
Masoud Fazlalipourmiyandoab ${ }^{1, *}$, Babak Nazari ${ }^{2}$ \\ 1Department of Statistics, Payame Noor University, PO BOX 19395 - 3697, Tehran, Iran \\ ${ }^{2}$ Teacher of Education in mentioned, Myandoab city, Box: 59716-55965, \\ West Azerbaijan provinces, Iran \\ *E-mail address: mesud.fq@gmail.com
}

\begin{abstract}
The aim of the present research was to investigate the relation of value inclinations and social identity-adoption (among the male high school students of the city of Myandoab in the educational year of 2012-2013). The research method was a survey type method and the statistical population included all the high school students of the city of Myandoab for as many as 2423 people. The number of the statistical sample of the present $t$ research with the Cochran formula is 292 where it increased to 300 for improving the accuracy. The sampling was done by simple random method. The tools for collecting data is the researcher made standard Finney questionnaire in two areas of social identity-adoption and value inclinations in the Likert scale where its face validity was reaffirmed by professors and the reliability was reported by using the Cronbach's alpha. The social identity - adoption was considered in two national and ethnic levels while the value inclinations were examined based on the Allport's six fold classification. The results findings revealed that other than economic values, there is a significant, direct and positive relation between the value inclinations and social identity-adoption of the students. The relation of value inclinations in artistic, scientific, and religious aspects is higher than the other relations.
\end{abstract}

Keywords: Value inclinations; Social identity-adoption; National identity; Ethnic identity; Students

\section{INTRODUCTION}

\section{Statement of the problem}

Asking about identity in the social theory, whether among the social psychologists or the sociologists has been intensely discussed, the main focal point of the discussion related with identity has been the fact that as a result of distinct structural and cultural changes that had occurred in the late decades of the twentieth century, transforming the world, coherent and relatively stable and traditional identities have been fraying and instead a multiplicity of sources of identification and collective affiliation have engendered in the fragmentation of the modern identity (Rafatjah, 2001). The social identity is primarily formed through social comparisons, comparisons that distinguish the inside and outside of the group.

Thus, if states and characteristics are defined for the person that would make sense only in relation with others and in comparison with others, his social identity is defined. All the 
characteristics and behaviors that lead to the distinction between "us" and "them" are regarded as the components of the concept of the social identity, e.g. language, religion, ethnicity and race, conventions and customs, social class, occupation, and collective and sect membership. The concept of the social identity implies a set of intergroup organized behaviors that are done as socially similar while the identification of social identities is an attempt for analyzing repeatable patterns of actions and collective attitudes (Abazari \& Chavoshian, 2003).

Thus, because the most important feature of the Iranian society, in the past century, has been the fact it has been transitional the developments related to transition from a traditional society to a modern society, quasi modern or untraditional and the issues related to the conflicts and contradictions between values and norms of the traditional cultural as having been undermined with values and norms of a modern and untraditional culture being created that exist and are real and on the other hand the fact they are not stabilized and are nor generalizable, hence, our country like most developing countries is faced with special issues of the transition era from tradition to modernity. Despite all the distinctions and exclusive and special aspects of the current Iranian society that would distinguish us from other countries going through the transitional trend, most general aspects of these developments have occurred in our country too, leaving their own peculiar consequences in the area of value inclinations. Values are opinions that people or human groups have regarding what is favorable or good, appropriate or bad. Different values are indicative of fundamental aspects of variety in the human culture (Giddens, 2008). Speaking of social properties, opinions, values and behaviors and distinct attitudes of social groups is as speaking of "social identity". In the simplest sense, the social identity is a definition the person has of him on the ground of membership in the social groups (Brown, 1985). Social values in all societies are favorable ends and objectives where people struggle to attain them so to meet their needs and wants. Value inclinations are thought the strongest determining element in a social, cultural and identity oriented system of any society that would navigate and supervise the trend of popular actions and conducts by peoepl.

They are also like relatively fixed conducts being continuously controlled and reviewed coherently. Understanding the social value system will get us acquainted with cultural elements and dominant identity of the society that directs to peoples' conducts and actions. By the same token, the aim of the present research was to investigate the relation of value inclinations and social identity-adoption (among the male high school students of the city of Myandoab in the educational year of 2012-2013).

\section{Research objectives}

General objective: Determination of relation between value inclinations and social identity-adoption of the students in the city of Myandoab in the educational year of 2012-2013. Specific objectives:

1. Determination of relation between inclination to economic values and social identityadoption of the male students

2. Determination of relation between inclination to social values and social identityadoption of the male students

3. Determination of relation between inclination to political values and social identityadoption of the male students

4. Determination of relation between inclination to aesthetic values and social identityadoption of the male students

5. Determination of relation between inclination to religion values and social identityadoption of the male students 
6. Determination of relation between inclination to scientific values and social identityadoption of the male students

\section{Theoretical basics}

In this research for investigating the predicting variable (value inclinations) the theory of cultural evolution by Engelhart was applied. For him, culture is a system of attitudes, values, and knowledge widely shared among peoepl and is transferred from one generation to another (Engelhart, 1993). He in relation with the question of why cultures evolve states: "any culture exposes the approach by in correspondence with the environment, generally these approaches will in the long run respond to some political, technological and economic transformations. Once a cultural transformation occurs when some large transformations are made in an economic and technological or sociopolitical environment.

For investigating the transformation of values, he raises two hypotheses of scarcity and socialization. In his view, the value transformations should be interpreted in relation with the hypothesis of socialization. The theory of socialization indicates that neither personal values nor values of a society will be totally changed overnight whereas the fundamental transformation of the values occur gradually and invisibly. Once this transformation occurs in a wide scale when a younger generation replaces the older one in an aged population of a society (Engelhart, 1993). Engelhart states that the relation between cultural and economic transformation is one of the causal mutual and complex relations, cultural factors not only are affected by the impacts of the economic transformation but they also affect it. The apparent decline of traditional religious and social norms is concerned with a transformation from material values to supra material values and it seems both processes are widespread cultural components where this is the feature of transition from an industrial society to Trans industrial society (Engelhart, 1993). Modernization has penetrated all the life aspects with large scale social variations and follows transformations in the social, cultural and political institutions and these results in different consequences in the cultural area, intergeneration changes, and changes to the universalities and values. Industrialization and modernization which are two main concepts in the social changes resulting from modernization will make fundamental changes to the attitudes and opinions, behaviors and social values of people from two technological and cultural aspects( Engelhart, 2010).

Industrialization develops the first major process of the cultural changes and follows secularism and bureaucracy. The emergence of the Trans industrial society will form the second major process of cultural changes: instead of rationality, centralization and bureaucracy, the new trend is directed towards increased emphasis on personal independence and values for self-expression. The modernization industrial stage will render in the secularization of authority, while the postindustrial stage will engender emancipation from authority. Thus, the socioeconomic expansion will result in two major aspects of intercultural changes; the former is concerned with industrialization while the latter is related with a postindustrial society (Engelhart, 2010).

The socioeconomic expansion will diminish objective constraints on independence, creativity and human choices. Reducing poverty by reducing material constraints on the human choice and by enhancing the sense of existential security plays a restrictive role. In this trend, the role of the cognitive mobilization also, matters. The socioeconomic expansion will increase the formal educational levels of people and provide the possibility to larger access to the information through making use of mass media.

Hence, another main impact of the socioeconomic expansion is that it will result on the reduction of rational limitations on the human choices in terms of cognitive and information 
aspects and add to the independent thinking of people. Changing from materialistic values to supra materialistic values is just one aspect of a larger change of modern values to postmodern values happening in an advanced industrial society. Postmodern values in most developing countries are unordinary. They are still changing from modern values. Both traditional and modern values have been formed by economic scarcity prevailing until recently. However, in the course of past several decades a new set of postmodern values has changed social, political, economic and gender norms. These new values represent the economic security conditions. If a person instead of feeling that it is unclear to continue this life is grown with a feeling of supposing the rest of the life as being decisive and definite, this will affect all the aspects of his universality. Postmodern values instead of compliance with authority emphasize on selfexpression and tolerate other groups and nevertheless place emphasis on external things and multiplicity of cultures as exciting and attractive not as threatening things. The modern industrial society perspective emphasize on the economic growth and economic accomplishments more than anything else.

Postmodern values prefer to maintain the environment and cultural subjects even when these objectives are in contradiction with maximizing the economic growth (Engelhart, 2003). Identity means the personal awareness of the "individuality" of the self and social "affiliation" and of course, this awareness is directed at that class of values and meanings which are of higher importance for the person. This awareness, though results from a process of individuation; it does not remain at a level of one internal and personal feeling while it will find a collective and external manifestation through showing the personal homogeneity and heterogeneity with others and different groups , thus, transforming into a foundation for social communication and political relations (Rahbari, 2009:19). To appraise the social identity, the identity theories could be categorized into two modern and postmodern approaches.

The modern approach is described by two narratives: one is the radical narrative in which freedom and awareness of man is regarded as the agent of knowledge and social action while the other narrative is conservative and is concerned with restrictive and discipline-oriented aspects of consequences resulting from modernity (Bashirye, 2001). This theory includes two major categories: sociological theories in which identity is made known by place and such sociologists as Giddens and Jenkins and the perspective of the symbolic reciprocity are classified in this category.

In the theories of the social psychologists, the personal mental processes play a necessary role in building up social identities. This perspective often overlaps with that of social understanding. In the postmodern approach it is believed that formation and definition of identity is done free from any manipulation by natural, mental and social entity. This theory is most recognized by a theory of discourse and is often affected by literature, linguistics and semantics. Postmodern emphasizes on the identities as being fluid and non-transparent and there are no pure, original and restrictive identities (Ibid, 86). The main theoretical framework of this research is constituted by the ideas of symbolic reciprocal actions (Jenkins and etc....). Jenkins and Giddens have considered the subject of structure and actions. On the ground of this insight, the society is the arena of collocation of micro and macro elements whose objective representation is based on plurality and acceptance of miscellaneous collective identities.

The Jenkins' perspective is for understanding identity, dialectic of identities and that of the self and the society as a whole that emphasizes on personal and social definition indicating a hermeneutic position (Jenkins, 2011). Giddens too maintains most people experience a coherent self and as a result they enjoy some existential security. He draws the issue of coexistence if micro and macro identities and defines types of identities at local and international level. To him, the more one knows the more cultures and identities will become 
prevalent and the personal identity is that should be created by person on daily basis and be supported in his reflexive activities (Giddens, 2008). The nature of social identities is hidden in values and cultural functions. Thus, the social identity is "defined as part of personal understanding of him that originated from his knowledge towards his membership in a social group where emotional values and senses are followed"

In societies with communicational collectivist values, social identification is at a high level by way of groups and emphasis on obligation, mutual dependence and responsibility towards the other groups as being members; because it is the groups that would provide security and guarantee safety. Cultural functions and values forming the implied rules of social interactions, expectation for mutual obligation and sources of social approval are decisive for a place wherein the person will invest his own definition, emotional attachment and more particularly his social identity.

\section{Background and literature review of the research}

Abaeikoopaei et al (2010), performed a research with the subject of the relation of a system of values and national identity of the students and the aim was to investigate the relation of a system of values and national identity of the students. The statistical population was all the boy and girl students at the high school level in the city of Tehran in the educational year of 2010. The sample size of 330 people was selected by using the multi stage random sampling and for collecting the data two questionnaires were applied: a). Allport, Vernon and Lindsey value system including 4 questions that measures six economic, social, political, scientific, artistic and religious components, b). The national identity questionnaire including 37 fie choice questions that constitutes seven aspects of social, historic , geographic, political, religious, linguistic and cultural identities.

Findings revealed that: 1 . The national identity of the students can be predicted through their value system scores. The power of predicting religious and economic values is more than that of theoretical, artistic and sociopolitical values. 2. A comparison of the scores average of values reaffirms the fact that the female students average higher in the artistic and social values compared to male counterparts while the boys average higher than girls in the rest values. No significant difference is seen in the religious and social values of the two sexes. 3. A comparison of average scores of the students' identity indicates that the social, historic and linguistic identity of the male students is stronger than girls while girls are stronger than boys in the political and geographic identities. But this difference is not significant in the national, religious, cultural and geographic identity.

In 2009, Elmi performed research with the subject of "students ' inclinations and value priorities and its relation with the social classes". The statistical sample of this research is 528 male and female students of the B.A. level in different majors of the University of Tabriz where from among 19052 students of this university they were selected by the Cochran formula and by way of classified random sampling in proportionate with the faculty and sex. Generally, based on the results of this research the value priorities of the students were obtained based on the average score as follow: social value (52/49), religious value $(52 / 03)$, theoretical and scientific value (51/98), economic value (49/51), political value (49/17), and aesthetic value (38/91). The Friedman test too specified a significant difference of value inclinations ranks. Various tests expressed the significant relation between religious value inclination and the social class.

Marzabadi (2008) performed a research titled as "investigation of relationship between the value system of the adolscents and national identity" and as many as 984 people (337 girls and 645 boys) were selected from among the high schools of the city of Tehran by using the 
cluster sampling method and survey type research. He demonstrated he had obtained the highest average from among the Schwartz' decalogue values and lowest average as from among traditions and debauchery stating there is a significant relation between the adolscents' inclination to the value system and their national identity. Moreover, findings suggest that there is a significant relation the adolscents' inclination to the value system and their national identity. The tools applied in here were two questionnaires of researcher made and Schwartz' periodical values whose validity and reliability were at a good margin. Taleban et al (2010) based on a secondary analysis of the results of the national surveys of 1974-2009 sought to investigate the trend of changes of the social values in the Iranian society at the current time period. The method for collecting data is documentation and the surveys extracted at the national level are applied. The findings are: 1 . The extent of the significance of the material values for the Iranian society from the $60 \mathrm{~s}$ to the third decade of the revolution has been on the rise, 2 . Ration of significance of most of spiritual value indices from the 60 s to the third decade of the revolution has been on the decline, 3. Extent of significance of material and spiritual values for the age group of over 50 (adolscents before the revolution) was higher than the age group of today adolscents.

Zolfalifam and Ghaffari (2009) carried out a research on the analysis of sociology of the social identity of the female students of the University of Guilan. The statistical population of 3800 people was consisting of the girl students studying at the University (admitted to the University from 1998-2001). They had been sampled as classified random sampling and 389 people were determined as sample size based on the Cochran formula. This research was done with a method of survey type and the findings revealed that girls see the readiness for accepting non-traditional role in them. Hence, it is observed over $60 \%$ of the girls have a clear imagination of non-traditional social roes while $28 \%$ are in an undecided situation. Regarding the authority of the traditional families whose non-acceptance is considered as the main basis for girls, it is confirmed based on data.

In other words, the modern generation will pass through the process of socialization outside of traditional patterns of the patriarch family. Findings revealed that over $60 \%$ of the girl students do not welcome the authoritative families and over $31 / 9 \%$ of the people are placed in between patterns and traditional and non-traditional thoughts. Totally, it seems the girls in the society attempt to go beyond the traditional social identity defined by the patriarch families by relying on non -traditional sources of identification like education, occupation, acquisition of traditional social identity, thus, striving to define for themselves non-traditional social identity.

\section{Research hypotheses}

1. There is a relation between inclination to economic values and social identity-adoption of the male students

2. There is a relation between inclination to social values and social identity-adoption of the male students

3. There is a relation between inclination to political values and social identity-adoption of the male students

4. There is a relation between inclination to religious values and social identity-adoption of the male students

5. There is a relation between inclination to scientific values and social identity-adoption of the male students 


\section{METHODOLOGY}

Due to the nature of the research and also the hypotheses and objectives defined the method of this research is a survey.

Statistical population, sample size and sampling method.

The research method was a survey type method and the statistical population included all the high school students of the city of Myandoab for as many as 2423 people. The number of the statistical sample of the present $t$ research with the Cochran formula is 292 where it increased to 300 for improving the accuracy. The sampling was done by simple random method.

The size of the statistical population $\mathrm{N}=2423$

The size of the statistical sample $\quad \mathrm{n}=332$

Possible favorable accuracy $\quad \mathrm{d}=0 / 05$

Confidence coefficient $\quad 95 \% \quad \mathrm{t}=1 / 96 \quad \mathrm{P}=0 / 5 \quad \mathrm{q}=1-\mathrm{p}$

$$
n=\frac{N t^{2} p q}{N d^{2}+t^{2} p q}=\frac{2423 \times(1.96)^{2} \times 0.5 \times 0.5}{2423 \times(0.05)^{2}+(1.96)^{2} \times 0.5 \times 0.5}=332
$$

If the ratio of $\mathrm{n}$ on $\mathrm{N}$ is equal or less than $0 / 05$ the resulting estimation of the first stage suffices while if the said ratio is greater than $0 / 05, \mathrm{n}$ should be corrected for the limited population. The $\mathrm{n}$ correction formula is as follows:

$$
n=\frac{n}{1+\frac{n}{N}}
$$

(Saraei, 2009:136).

The sample size was obtained as 292 where for increasing the accuracy, 300 more were added.

$$
\begin{gathered}
\frac{n}{N}=. / 1 \\
n=\frac{n}{1+\frac{n}{N}}=\frac{332}{1+\frac{332}{2423}}=292
\end{gathered}
$$

Table1. Statistical population and sample.

\begin{tabular}{|c|c|c|c|c|c|c|c|}
\hline \multicolumn{3}{|c|}{ Statistical population } & \multicolumn{3}{c|}{ Sample population } \\
\hline $\begin{array}{c}\text { First } \\
\text { grade }\end{array}$ & $\begin{array}{c}\text { Second } \\
\text { grade }\end{array}$ & $\begin{array}{c}\text { Third } \\
\text { grade }\end{array}$ & Total & $\begin{array}{c}\text { First } \\
\text { grade }\end{array}$ & $\begin{array}{c}\text { Second } \\
\text { grade }\end{array}$ & $\begin{array}{c}\text { Third } \\
\text { grade }\end{array}$ & Total \\
\hline 1366 & 604 & 453 & 2423 & 165 & 73 & 54 & 292 \\
\hline
\end{tabular}


The sampling method is simple random method. At first, the Myandoab high schools were classified into five classes based on the geographic situation where the first class included north western high schools, second class included north eastern high schools, third class included central high schools, fourth class included south western high schools and the fifth class included south eastern high schools. Then, from inside of each class a number of high schools were randomly selected and in the end, from among each high school some students were selected as samples.

\section{Measurement tools}

The measurement tool for the information in this research is questionnaires. Here in this research the Finney standard questionnaire has been used to gauge the social identity divided into two aspects of national and ethnic identities and then, the questions for measuring the value inclinations are made by the researcher.

\section{Measurement of variables}

The value inclinations aspects as the predicating variable in accordance with the scale of the Allport, Vernon and Lindsey standards have been divided into six parts where each of the values is measured by items on the Likert scale. These values are 1. economical, 2. social, 3. political, 4. artistic, 5. scientific, 6. religious.

In this research the criterion variable is the social identity-adoption where from its aspects two dimensions of national and ethnic identity were measured. The national identity questions are 8 being measured by the Likert spectrum on a 5 degree scale and its indices are: being proud of being Iranian, having a main role of being Iranian in life, having a good feeling of being Iranian, knowing each citizen as being compatriot, feeling of attachment to the Iranian culture and history, calling oneself Iranian, being unhappy when criticizing Iran by others. To measure the ethnic identity, the six Finney standard items measured on a five degree scale were used.

The indices are: attempts to obtaining information from a self-responding ethnic group feeling of strong attachment towards ethnic group, feeling of dependence to an ethnic group.

\section{Reliability and validity of the measurement tool}

The reliability of the questionnaire is of face validity and to measure the reliability of the questionnaire questions the statistical Cronbach's alpha test was applied so that by estimating this coefficient the internal reliability of the items is understood. The Cronbach's alpha range is from $0-1$ where in this coefficient zero is an indication of unreliable items and hence, the extent of the estimated alpha for all the components is greater than $0 / 7$.

\section{FINDING}

To analyze the data the SPSS statistical software version 19 was used. To test the hypotheses the Pearson correlation coefficient test was applied.

\section{Data description}

The six fold values of the research under study are in relation with the social identityadoption and other than the economic values their positive and direct relations was proved. Table 2. Shows the main subject of the research comprehensively (relation of values with social identity-adoption). 
Table 2. Comprehensive results of the correlation relation of the values and social identity - adoption.

\begin{tabular}{|c|c|c|}
\hline Subject & \multicolumn{2}{|c|}{ Social identity-adoption } \\
\hline Value & $\begin{array}{c}\text { Correlation } \\
\text { coefficient }\end{array}$ & Sig. \\
\hline Economic values & 0.022 & 0.700 \\
\hline Social values & 0.75 & 0.002 \\
\hline Political values & 0.151 & 0.009 \\
\hline Artistic values & 0.222 & 0.000 \\
\hline Religious values & 0.380 & 0.000 \\
\hline Scientific values & 0.246 & 0.000 \\
\hline
\end{tabular}

\section{CONCLUSIONS}

The research sought to answer the question of whether there is a relation between the value inclinations and social identity-adoption of the students. In other words, the research aimed to investigate the relation of the value inclinations and the social identity - adoption of the students. In this regard, by doing some statistical tests on the researches of the research it was made clear that there is a significant relation between the value inclinations and the social identity-adoption of the students. Results of this research regarding the first hypothesis indicate that there is no significant relation between the economic values and social identity-adoption, i.e. with increase of economic values the extent of social identity-adoption will not increase by the same extent. To explain the finding we can say that values are overall beliefs of one person and groups of people about conducts and actions and thoughts considered as the most important determining factors of the conducts of the members of the society while being the cornerstone of the society as a whole. That which is interested by an economic human is the usefulness of objects which is first based on a satisfaction of bodily needs, such things as production, marketing, introduction of goods, financial credits and accumulation of wealth. Economic inclination is mostly in contradiction with other values. The economic human in his relations with people seeks to dominate them in terms of wealth than providing service to them. Thus, groups that have higher economic values are found to be in a lower social identity-adoption in terms of correlation. The second hypothesis of the research is whether there is a relation between inclinations towards social values and social identity-adoption which was affirmed by the Pearson correlation test. In relation with this hypothesis, the results by Elmi (2009), indicated that the highest extent of value inclinations is related with social values whose average is 52/49 among the students under study.

To explain these findings we can say that people having higher inclination to social values are generally found to have morale of self-dedication, friendliness and sacrifice and their social behavior are formed by group attachment and by the feeling of their obligation towards groups. Students are more inclined to collectivism. In other words, they have collectivism values. The third hypothesis of the research was about the relation between the inclination towards political values and social identity-adoption and this was affirmed by the Pearson correlation test. In relation with this, results by Taleban et al (2010) regarding political participation and obtaining 
state posts showed there are consistent reports. The average inclination to political values of the students is consistent with the findings of the research by Elmi (2009). To explain the findings we can say political values expose higher variability. In other words, inclination to obtaining state posts and participation in election are averaged higher while membership in the political parties is found to be averaged lower. Maybe, this is due to greater consequences of political activities in the future years of social, economic and occupational life. Of course, usually negative and pessimistic experiences of the families could affect this perspective. We can say since a scientific human has a cognitive inclination and is apt to reasoning and contemplation his attachment and obligation to the social identity and acquaintance with the aspects of the social identity is a clear thing while he has a strong bond with his social identity.

The sixth hypothesis states that there is a relation between inclination to religious values and social identity-adoption which was supported by the Pearson correlation test. Abaeikoopaei et al (2010) in their investigation of the relation of the value system with the national identity and the fact religious values are strong predictors found out that there is a significant relation between inclination to religious values and social identity-adoption. These findings revealed that the students being more familiar with religious values, this inclination is in correlation with their national identity. Results of various researches have indicated that the system of values form the social identity. Values in fact, are basics for understanding peoples' actions and behaviors and base on their values inclinations their social identity could be investigated and analyzed. In fact, the value inclinations will promote the identity aspects of the person and consolidate the personal orientation in relation with culture, nationality, religion and society as a whole. The ranking of the values in the current paper is based on six components by Allport, Vernon and Lindsey which are artistic, scientific, religious, social, political and economic values respectively. The theoretical concepts of this research are based on a fusion of theories by scientist of the school of the mutual symbolic actions. The fundamental concept in this school is "self" and how this "self" is made. On the ground of the theory of "self" an operant is formed in interaction with other operant and thus, nature is formed. On the other hand, based on the symbolic mutual action, "self" being a fundamental concept of a theoretical perspective is understood as a hierarchy of identities adjusted on importance degree, thereby, modifying the operant' $s$ behaviors in social interactions.

According to a theoretical background the social identity will create a framework through which differences and similarities will arise. Establishment of a social identity means an application of methods a ways by which people and groups are distinguished and such similarities and differences are dynamic principles of the life social identity. Social identity is concerned the identification of self in relation with others. From this perspective, the personal social identity will be fulfilled through membership in various social groups. Values as special social wants and desirability have systematized the social identity and constitute the cultural identity of the society. The value orientation is a main social action orientation and the stability of cultural patterns depends on that of pivotal values of the society. This will once be fulfilled when the members of the society participate in institutionalized and internalized processes of the values in the society and accomplish them. Continuation, interaction, survival and stableness of a society will greatly depend on contributory values in that society. The social action in the Parson's sense includes all the human behaviors whose motivation and guidance is senses discovered in the real world by the operant. Thus, the main characteristics of the social action is in the sensitivity of the operant towards the senses of the objects and entities existing in the environment and is also awareness of this sense that in four elements, the personal or social operant or his social and physical status are affected by some icons which have been meaningful that adjust the orientation of actions based ion values. In fact the social identity of 
the person is made by his attachment and obligations to social groups. Values as included in the main social features and as social phenomena are thought as pivotal in formation, controlling and prediction of actions and orientations of the peoples in the society. They are also considered as pivotal element in the cultural structure of the society and are observable in the political, social, economic, religious and artistic aspects in the long and short term due to immense impacts they engender. Because the basic of the social identity is based on the social membership and group attachment in proportionate with social value orientation, the identity is an acquisition and fluid thing evolved in the technological, political and economic developments.

Due to the fact the results of the paper suggest the impact of the value system of the students it is necessary judgments in this regard and planning for improving the value system and growth of social identity-adoption be done in relation with factors. The education department should also work to promote the values system of the students by providing educational-mental counseling for eliminating the students' problems. Also, the students ' value system will shape their behaviors and due to the fact that the strength of the social, familial, and religious values leave the greatest impact on the adolscents' social identity-adoption, it is imperative plans be done. Unfortunately, in high schools training personalities and education identity and value system of the students have not been performed so coherently and this weakness should be attended to immediately.

\section{References}

[1] Abaeikoopaei M., Ahghar Gh., Ramazanpoor F., Quarterly of national studies 44 (2010) 3-26.

[2] Abazari Y., Chavoshian H., Social sciences letter 20 (2002) 3-27.

[3] Engelhart R. ( 2010). Renewal, cultural changes and democracy, Trans, by Yaghoob Ahmadi, Tehran: Kavir publication.

[4] Bashirye H., Naghed journal 2 (2001) 13-30.

[5] Brown R. (1985). Social identity, in Adam and Jessica Copper (eds) The review of Social Sciences Encyclopedia, London, R.K.P.

[6] Castells M. (2003). Age of information: economy, society and culture of the power of identity, Second Vol, Trans, by Hasan Chavoshian, Tehran: Tarhe No publication.

[7] Giddens A. (2008). Sociology Trans, by Manoochehr Saboori. Tehran: Nei publication.

[8] Elmi M., Applied Sociology 34(2) (2009) 107-132.

[9] Engelhart R. (1993). Cultural revolution in the industrial advanced society, Trans. By Maryam Vatr, Tehran: Kavir publication.

[10] Engelhart R., Iraj Feizi, Research letters 6 (2003) 109-128.

[11] Jenkins R. (2011). Social identity, Trans by Tooraj Yarahmadi. Tehran: Shiraze publication.

[12] Marzabadi E., Quarterly of national studies 9(34) (2008) 113-132.

[13] Taleban M. R., Mobasheri M., Mehraeein M., Social sciences 3 (2010) 23-66.

[14] Zolfalifam J., Ghaffari M., Adolscents research, Culture and society 3 (2009) 120-140. 
[15] Heman Mahmoudfakhe, Morad Abdivarmazan, Toba Amini, International Letters of Social and Humanistic Sciences 15(2) (2014) 84-91.

[16] Sule Maina, International Letters of Social and Humanistic Sciences 4 (2014) 87-96.

[17] Mohamad Khaledian, Galavizh Khaledian, Jabar Sadeghi, Reza Keyhanihekmat, International Letters of Social and Humanistic Sciences 6 (2013) 62-67.

[18] Mohamad Khaledian, Zahra Ahmadimehr, Elham Naseri, Fakhralsadat Khosravani, Mojgan Shoshtsri, International Letters of Social and Humanistic Sciences 8 (2013) 43-48.

[19] Hamid Kamarzarin, Maryam Tehranizadeh, International Letters of Social and Humanistic Sciences 19 (2014) 69-80.

[20] Siamand Movloudi, Heman Mahmoudfakhe, International Letters of Social and Humanistic Sciences 22 (2014) 1-7. 